\title{
Sheffield Laboratories for Safety in Mines Research.
}

\section{By H. F. COWARD.}

THE special dangers of the coal-miner's work have always aroused sympathy from the public, who have been generous in helping the families of miners killed in great colliery disasters. Preventive measures to avoid these dangers have been based on the occasional assistance of students of natural science, as when Humphry Davy invented a safety lamp, and on the continuous efforts of mining engineers. The methods of experimental science were not applied systematically until about twenty years ago, when the Mining Association of Great Britain-a body of colliery owners-set up a full-scale gallery at Altofts, in Yorkshire, to demonstrate the explosibility of a cloud of coal dust and to test the efficacy of stone dust as a means of preventing coal-dust explosions. The success achieved led the Home Office to build a more elaborate station at Eskmeals, on the $\mathrm{Cum}$ berland coast, for the experimental study of dust and gas explosions with the view of the development of means for preventing such disasters underground. The War brought this work almost to an end, but it was revived by the Miners' Welfare Fund Com mit te e, which has enabled the Safety in Mines Research Board to build a largescale experimental station near Buxton and laboratories in Sheffield.

On Thursday, Oct. 11, the Sheffield laboratories were formally opened by the Prime Minister, who made a tour of them, accompanied by Mrs. Baldwin, and witnessed a number of experiments. In his address, Mr. Baldwin said that he had been assured that the mines of Great Britain to-day are the safest in the world, and asserted that "they have got to be a great deal safer-both our mines, and mines throughout the world." He met an American research worker in the new laboratories. "There is already with America an interchange of personnel and information, similar arrangements have been concluded with France, and preliminary inquiries are being made as to the possibility of extending this system to other countries. . . There may yet come a day when the great mining industry may be as safe, as far as danger to life and limb is concerned, as any industry on the surface of the earth."

The valediction of Mr. Herbert Smith, president of the Miners' Federation, was equally plain: "Compensation can't put limbs on or give life back. . . When the miners lost about 100 per month through fatal accidents, when 400 a month were lamed seriously, and when about 16,000 played more than 3 days a week, they were anxious that research should go on ....," he would say, "Go on with your good work and God bless you."

Other speakers at the ceremony were Commodore King, Secretary for Mines (in the chair); Lord Chelmsford, chairman of the Miners' Welfare Committee; Mr. Evan Williams, president of the Mining Association of Great Britain ; and Sir Edward Troup, chairman of the Safety in Mines Research Board.

The new building (Fig. 1) is adjacent to the Department of Applied Science of the University of Sheffield, thereby securing for the staff close contact with the varied activities of a university. It has four floors and a basement, and the construction is such that two more floors can be added if required. As arranged at present, most of the twenty-four laboratories are small, and only adequate to house one investigator in each. Their size is, however, adjustable ; for the partitions are light and can readily be removed if it becomes desirable to form larger rooms. The fittings and services have also been designed so as to enable quick and economical readjustment to meet the changing needs of research.

A portion of the new building has been allocated to the Fuel Research Board for use by the South Yorkshire committee for the survey of the national coal resources. The work of the investigators on the composition and properties of coal is closely allied with one part of the Board's work, and the association will be of mutual benefit.

The new laboratories, as well as the large-scale station at Buxton, are under the direction of Prof. R. V. Wheeler, who has been responsible for the scientific direction of such work in the twenty years since its inception at Altofts, by the Mining Association of Great Britain, under the general direction of Sir William Garforth.

\section{Research in Progress in the NeW LABORATORIES.}

Coal-Dust Explosions.-The experiments at Eskmeals proved that when sufficient incombustible matter is mixed with coal dust, an explosion of a cloud of the mixture is impossible. What research and experience recommended as the best practice was, in 1920, embodied in coal-mining regulations, and the happy result has been that no serious eoal-dust

No. 3077, VoL. 122] 


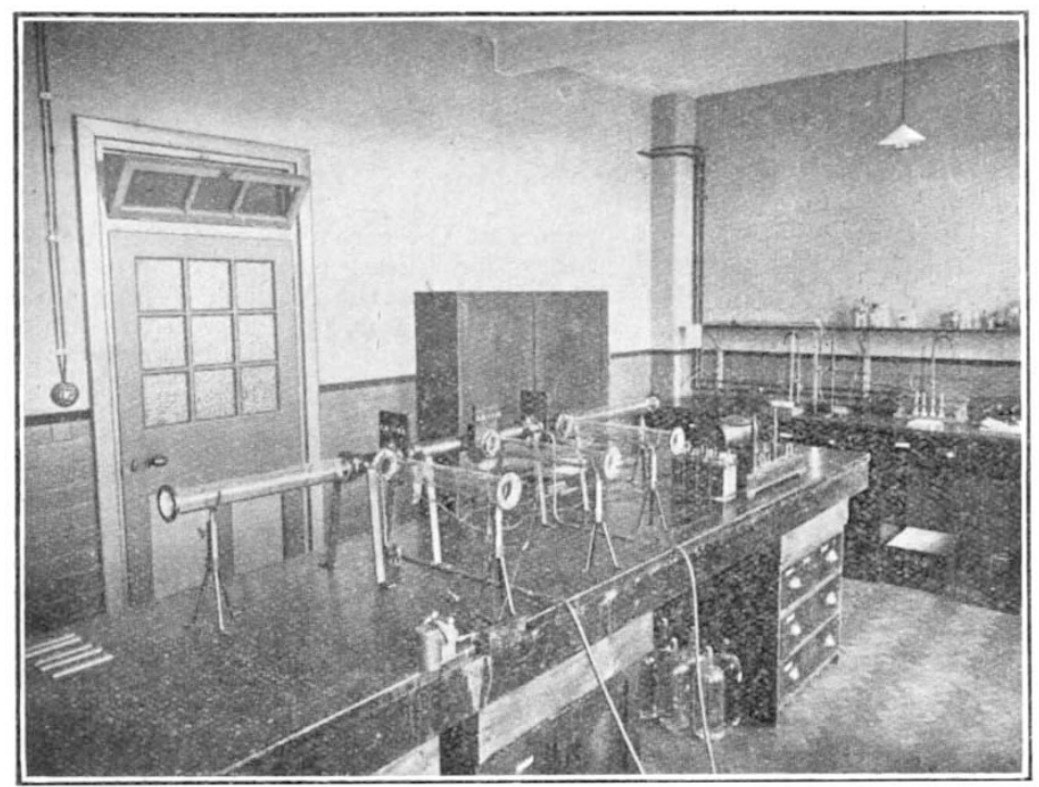

FIG. 2.-A laboratory fitted for flame research. Apparatus for observing the projection of flame in branched galleries; glass and metal tubes represent galleries which may be shut off at desired points by sliding partitions.

explosion has yet occurred in Great Britain in a pit treated with the required amount of stone dust.

The outstanding question to be answered is, whether the means now used to prevent coal-dust explosions always give adequate safety, and, if not, what improvements are possible. Different samples of coal dust differ greatly in explosibility, according to their physical state and chemical composition. One line of research is therefore planned to determine the effect of fineness on explosibility, another to compare the explosibility of a series of different coals ground to a powder which, so far as can be determined, is of the same average fineness for all. To save the time and cost of much of the large-scale experimentation which might be conducted for these objects, laboratory methods are being examined and have proved, so far, to give results parallel to those obtained in the fullscale galleries at Buxton. Both laboratory and field experiments on dust explosions, however, are empirical; a concentrated effort is therefore in progress to determine the composition of coal, not only for the sake of measures for preventing coal-dust explosions, but also for controlling the self-heating of coal in the wastes and in crushed pillars of coal in the mine.

Spontaneous Combustion of Coal.-Many mining engineers have experienced the difficult and dangerous task of fighting underground fires which have originated in the spontaneous combustion of some part of the coal substance. Experience has shown that certain seams are more liable to fires than others, and that some methods of mining lead to much less frequent fires than others. The experimental study of the spontaneous combustion of coal is a laboratory supplement to the engineer's observations underground.

Of the four macroscopic constituents of coal, namely, vitrain, clarain, durain, and fusain, the last named is the least readily oxidised and would therefore appear to contribute least to spontaneous heating. It is, however, the most porous and friable constituent, and therefore permits air to diffuse to the more oxidisable parts when a mass of coal is crushed. The function of pyrites is not yet fully understood, but its oxidation produces crystalline products of greater volume than the pyrites from which they were formed, and thus breaks up the mass to make way for the entrance of air.

The most readily oxidisable ingredient of coal has proved to be the ulmin fraction, which forms the major part of a vitrain and a clarain and a high proportion of a durain. The ulmin fraction is, however, not of constant composition, and variations in the oxidisability of coal are largely attributable to variations in the composition of the ulmins present.

Firedamp Explosions. - In the early days of coal-mining the danger of firedamp was met by the hazardous method of igniting the gas before it had accumulated in formidable amounts. This primitive procedure has long been superseded by improved ventilation designed to keep the amount of firedamp everywhere below the explosive limit, and by safety lamps designed in such a manner that they will not pass flame into the air in the event of the atmosphere becoming abnormally charged with firedamp. These precautions have enormously reduced the danger, but explosions still occur, sometimes with fatal results.

Research on firedamp explosions is directed towards discovering the conditions of ignition of firedamp and the mode of propagation of flame in mixtures of firedamp and air, so that suitable measures can be taken to avoid ignition underground and to prevent the spread of flame. Mining equipment, such as lamps,

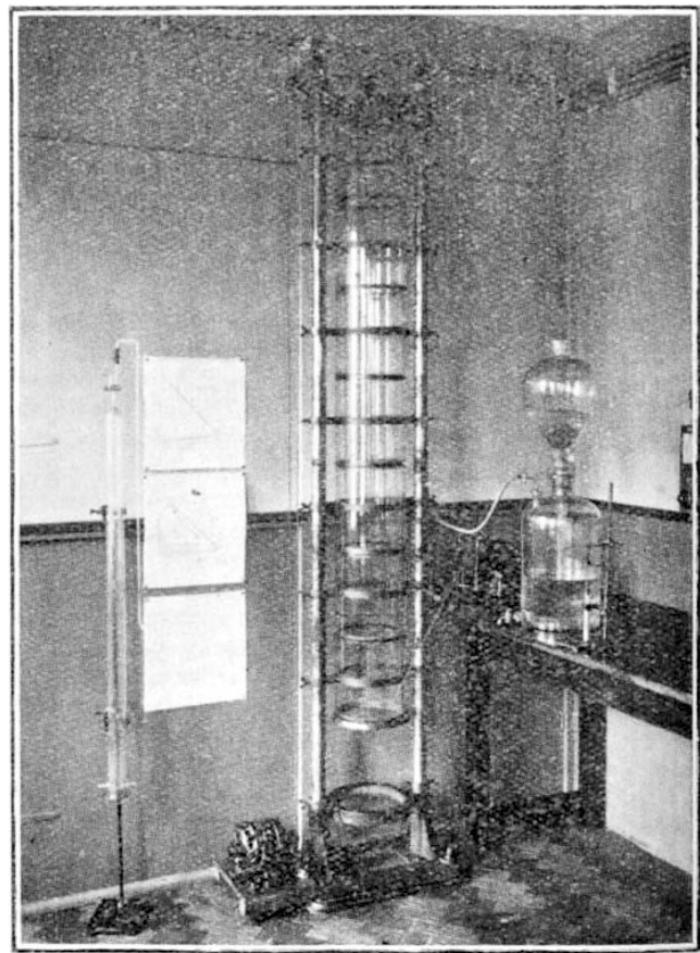

Fro. 3.-Apparatus for determining the limits of intrammability of gas mixtures. The narrow tube on the left is used for long series of experiments, and the applicability of the results to practical conditions is tested by the larger tube in the centre.

No. 3077, VoL. 122] 
switches, and motors, are fitted with the safety devices suggested by research, and are tested in explosive atmospheres composed of firedamp and air in the proportions which give the most stringent test in the circumstances. For underground signalling by bells and telephones, the design of electric circuits has been so improved as to render the spark at break unable to ignite firedamp.

An extensive investigation of the danger of friction sparks from picks and coal cutters, and of electric sparks due to the spontaneous generation of electricity in a cloud of coal dust, is approaching completion.

Electrical Researches.-Apart from the investigations named above, the chief object of the electrical researches in the new laboratories will be to improve the safety of the electrical equipment necessary for increased illumination of the mine; for better illumination will not only enable the collier to avoid many accidents, but also will, it is believed, prevent the eye disease called miners' nystagmus.

Mining Explosives. The official safety test for mining explosives was designed to be more severe than the conditions of the pit, but explosives which have passed the test have proved not to be safe in all circumstances. It seems impossible, at the moment, to propose any improvement on the test, for want of exact knowledge of the mode of ignition of gas by an explosive. The subject is under investigation by the Board, but the work has been mainly transferred to the Buxton station.

Safety Lamps.-Flame safety lamps have been studied in detail during recent years, and much improved illumination obtained by suitable modifications. in design and suitable blendings of lamp oils. The results of these researches are in the hands of manufacturers, and experimental lamps are receiving trial underground.

Mine-Rescue Apparatus.-Self-contained breathing apparatus provides a supply of oxygen independent of the atmosphere, and is necessarily somewhat heavy and cumbrous. It may frequently happen that a suitable gas mask could be substituted, and attempts are being made to produce one which contains sufficient absorbents to remove all noxious gases, including carbon monoxide, and yet not to offer so much resistance to the passage of air that the wearer is hampered. A study of carbon monoxide estimators, and the construction of a portable oxygen estimator, are also contemplated.

\section{The University of Leeds.}

\section{Extension of the Textile Industries Departinent.}

$\mathrm{O}^{\mathrm{N}}$ Thursday, Oct. 12, the Master of the Worshipful Company of Clothworkers of the City of London opened the new extension of the Clothworkers' Departments of the University of Leeds, the buildings of which have cost approximately $£ 12,000$, and the equipment, largely provided by donors in the textile industry, another $£ 10,000$. The extension has been designed to facilitate (1) the installation of an experimental wool plant covering all the processes for the woollen and worsted industries ; $(2)$ the extension of museum and laboratory accommodation to fulfil the requirements of a much larger number of postgraduate and degree students attending the department; and (3) to provide additional accommodation for the Sill Research Association which is housed within the University precincts.

It is fifty-four years since the Clothworkers' Company gave the first donation which enabled the Textile Industries Department to be installed alongside the Science Departments in the then Yorkshire College of Science. Largely owing to the traditional character of the wool industries and the complexity of the wool fibre and wool processes, the bearings of science upon the technology of the subject have not vet been completely realised, but an additional grant from the Clothworkers' Company of $£ 4000$ a year has made it possible to appoint, within the Department of 'Textile Industries, a science staff which, working along with the technological staff, is already showing promise of that association between science and technology which was the primary object of the Clothworkers' Company.

The complete equipments in the woollen and worsted manufacturing processes will enable the technological staff to define clearly miny of the fundamental problems of the industry which in normal practice are hidden owing to a conglomeration of varying factors; and then, with the more refined 'tools' now available, the scientific worker is at hand either to solve the problems in question or to suggest the scientific tools which will help the technologist towards more perfect methods of manufacturing.

At the opening ceremony the Master was supported by a large gathering of representatives from the whole of the woollen and worsted industries and by other supporters of university developments in Yorkshire. The Pro-Chancellor of the University of Leeds, in introducing the Master, gave a history of the association of the Clothworkers with the University, which showed that grants of $£ 100,000$ for accommodation and equipment and $£ 165,000$ for maintenance had already been made, and that in addition to these a grant of $£ 4000$ a year had been raised to $£ 7000$ a year.

The Master, in declaring the buildings open, spoke of the intense interest the Clothworkers' Company takes in the extension of their departments of the University, and expressed his appreciation that the generosity of the Company has met with such a hearty response from the machine makers of Yorkshire and elsewhere. He congratulated the University on the progress it is making, and hoped that the present scheme would fulfil the anticipations of its promoters. The Vice-Chancellor, Dr. J. B. Baillie, and the chairman of the Advisory Committee, Mr. A. Michael Lupton, thanked the Clothworkers for their munificence, and the latter, in seconding the vote of thanks, emphasised the large amount of graduate and post-graduate work which is now being undertaken in these departments. Prof. A. F. Barker, on behalf of the staffs of the departments, and Mr. George Blackburn, on behalf of the past and present students of the departments, also supported the vote of thanks. The architect, Mr. Waterhouse, presented the Master with a key of the building, and the guests then made a tour of inspection.

In the equipment it is interesting to note the comprehensive display of such things as electric driving and lighting, air conditioning, floors and other matters appertaining to recent developments in factory construction and running. In other respects the equip. ments are representative of the latest practice, and almost without exception the firms involved have agreed to keep this equipment thoroughly up-todate. Thus, not only will the equipment be used for teaching purposes, but also for experimental purposes on lines which will make a very strong appeal to those who are endeavouring to keep the textile industries of Great Britain well ahead in all manufacturing processes.

No. 3077, VoL. 122] 